\title{
INSPECCÃO PREDIAL: PERSPECTIVAS ATUAIS E FUTURAS DIANTE DO CENÁRIO DE COLAPSOS ESTRUTURAIS OCORRIDOS NA CIDADE DE FORTALEZA/CE EM 2019.
}

\author{
ANTUNES MONTEIRO, ADRIANO \\ Profissão: Estudante \\ Instituição: ESITC \\ Estado; País: Normandia, França \\ e-mail: adrianoantunesmonteiro@gmail.com
}

\author{
MELO MONTEIRO, ADRIANE \\ Profissão: Estudante \\ Instituição: IFCE MARACANAÚ \\ Estado; País: Ceará, Brasil \\ e-mail: driane.mello@gmail.com
}

\author{
TEIXEIRA DA SILVA, KAROLINE \\ Profissão: Estudante \\ Instituição: ESITC \\ Estado; País: Normandia, França \\ e-mail: karolinetx@gmail.com
}

\author{
PIRES BEZERRA, JORGIANE \\ Profissão: Estudante \\ Instituição: IFCE MARACANAÚ \\ Estado; País: Ceará, Brasil \\ e-mail: jorgianepires@gmail.com
}

\section{RESUMO}

Nos últimos anos as discussões sobre a fiscalização e regulamentação da Lei de Inspeção Predial vêm sendo esquecida na cidade de Fortaleza, desta maneira, este serviço acaba sendo subvalorizado e por vezes negligenciado. Em paralelo à estas circunstâncias, patologias em edifícios surgem diariamente e em alguns casos podem alcançar grandes dimensões e causar o colapso estrutural das edificações como foi observado recentemente em dois desabamentos de prédios ao longo do ano de 2019 no município de Fortaleza, trazendo grande repercussão nacional. Assim, este artigo busca mostrar como se encontra o atual cenário municipal na fiscalização da atividade de inspeção predial em Fortaleza e suas perspectivas futuras para a aplicação da lei, diante dos incidentes estruturais ocorridos na cidade, e como a concordância deste serviço corrobora para a identificação, tratamento e eliminação de patologias nas edificações, com a finalidade de redução de falhas em todos os níveis de gravidade.

Palavras-chave: Colapso Estrutural, Fiscalização, Inspeção predial, Patologias em edifícios.

\begin{abstract}
In recent years, discussions about the inspection and regulation of the Building Inspection Law have been forgotten in the city of Fortaleza, so this service ends up being undervalued and sometimes neglected. In parallel to these circumstances, pathologies in buildings appear daily and in some cases can reach large dimensions and cause the structural collapse of buildings as was recently observed in two building collapses in the year 2019 in Fortaleza, bringing great national repercussion. Thus, this article seeks to show how the current municipal scenario is in the inspection of the building inspection activity in Fortaleza and its future perspectives for law enforcement, given the structural incidents that occurred in the city, and how the agreement of this service corroborates the identification, treatment and elimination of pathologies in buildings, with the purpose of reducing failures at all levels of severity.
\end{abstract}

Keywords: Structural Collapse, Surveillance. Building inspection, Pathologies in buildings.

\section{INTRODUÇÃO}

No que se refere a execução de construções verticais, a sua concepção tem por objetivo a promoção do conforto, segurança e qualidade de vida para os seus moradores. Desta maneira, o termo que melhor engloba tais características, é o desempenho e começou a ser bastante usado na descrição dos procedimentos em utilização em uma construção e em todos os seus sistemas compreendidos, seu marco inicial se deu a partir do ano de 2008 com surgimento da NBR 15.575 (ABNT, 2013). 
A norma técnica 15. 575/2013 define o desempenho das edificações, com isso, ela estabelece os parâmetros mínimos para a segurança, habitabilidade e sustentabilidade, assim, a mesma procura instituir as condições ideais dos materiais e métodos construtivos e também se atenta após à construção, ou seja, regulamenta os resultados construtivos obtidos, desta maneira, garante a funcionalidade adequada de todas as partes de uma edificação sob uma visão holística (ABNT, 2013).

As norma e regulamentações quanto ao desempenho das edificações se fazem importantes, pois, os grandes centros urbanos se destacam por sua quantidade de edifícios existentes que compõem um dos principais eixos edificados de uma nação. Neste sentido, percebe-se que muitos se encontram bem antigos, ou seja, extrapolando o tempo de vida útil previsto em projeto, ou quando os mesmos não apresentam manutenção adequada, acabam exibindo deterioração precoce, e no pior dos casos, as edificações não recebem atenção nenhuma, que permite uma degradação sem controle. Assim, é necessário que tais edifícios apresentem planos para evitar o aparecimento de problemas e reparos de suas patologias que possam existir (VIEIRA, 2015).

Nas construções verticais, a falta de inspeção e manutenção predial em todos os sistemas e subsistemas envolvidos acarreta um aumento na probabilidade de acidentes, causados por vezes, por colapsos estruturais totais, atingindo em sua maioria as pessoas que habitam estas propriedades podendo gerar perdas humanas, ou colapsos parciais, como o desprendimento de forros ou desabamento de fachadas, que podem alcançar pessoas que passam perto destas estruturas, devido a sua localização acima de calçadas (OLIVEIRA, 2013).

Assim a inspeção em edificações pode ser dita como a "[...] análise técnica de fato, condição ou direito relativo a uma edificação, com base em informações genéricas e na experiência do engenheiro de diagnóstico [...]” (GOMIDE et al., 2009, p.14), ou seja, compreende em um conjunto de ações que procura identificar possíveis patologias nas construções, ou ainda, condições de riscos que possam gerar futuras degradações nestes ambientes, assim, apontar soluções para eliminar os danos identificados (VERVLOET, 2018).

Neste contexto, é importante reconhecer que diversos acidentes marcaram negativamente a construção civil no estado do Ceará, principalmente em sua capital e maior cidade, Fortaleza, pois, no ano de 2019, dois colapsos estruturais foram destaques na mídia em nível nacional, seja, pela quantidade de vítimas alcançadas, ou pelas negligências em projetos, manutenção e fiscalização das inspeções prediais.

No dia 01 de junho de 2019, aconteceu o desabamento da parte de um edifício, localizado no bairro de Maraponga, na zona sul de Fortaleza, ganhou destaque no noticiário nacional, devido, as imagens e vídeos, onde pode-se visualizar o momento exato do rompimento dos pilares de sustentação do prédio, neste fato, não houveram vítimas, pois na noite anterior a tragédia, foram escutados estalos na estrutura e os moradores do condomínio e casas do entorno foram evacuados às pressas do local e a área foi isolada (ALMEIDA, 2019).

Já no dia 15 de outubro de 2019, o colapso estrutural total do edifício Andreia, prédio residencial de 7 pavimentos situado no bairro de Dionísio Torres, área nobre de Fortaleza, deixou 9 mortos e dezenas de famílias desabrigadas, o fato causou grande apreensão, visto que existiam fortes indícios de vítimas ainda com vida embaixo do prédio, ao todo foram retiradas do 9 pessoas com vida dos escombros da construção, foi verificado que o mesmo já era bem antigo, e se encontrava em grave estado de deterioração (FREITAS, C.; XEREZ, G.; ALMEIDA, 2019).

Com o decorrer das investigações do primeiro fato foi observado que começou na cidade um período de discussões no meio da construção civil e entidades públicas sobre a importância da inspeção predial para evitar que episódios como esse ocorram novamente, fato este que foram agravados com este novo episódio, visto que a prefeitura de Fortaleza não tinha nenhum documento oficial que atestasse a existência do prédio, ou seja, o edifício era uma construção fantasma, que revela o quão negligenciado e desorganizado é a fiscalização e gerenciamento de inspeção predial na capital cearense.

Desta maneira, o presente artigo tem por objetivo um esforço de acompanhar o processo de regularização, diagnóstico e fiscalização da inspeção predial na cidade de Fortaleza frente aos últimos colapsos estruturais e parciais ocorridos na cidade durante o ano de 2019, com o intuito de investigar os argumentos técnicos estabelecidos pelas entidades representantes da construção civil e pelo poder público para a atividade na capital do Ceará, assim determinando o cenário atual e as perspectivas futuras de todas as etapas que compreende esta atividade.

Assim, esta pesquisa se justifica, portanto, pela relevância do tema, além de ser uma atividade extremamente necessária e bastante discutida na atualidade devido aos vários episódios que poderiam ser evitados em um cenário de adequada aplicação da inspeção predial. 


\section{INSPEÇÃO PREDIAL}

No Brasil, o histórico desta atividade pode ser considerado recente, pois, remonta ao ano de 1999, onde, no décimo congresso brasileiro de engenharias de avaliações e perícias (COBREAP), na cidade de Porto Alegre, foi apresentado o trabalho técnico: "A Inspeção Predial deve ser periódica e obrigatória? ”, que retrata a importância da manutenção das edificações para a conservação estrutural, que marcou o início das discussões sobre a importância do tema no país. (GOMIDE, 2013).

A inspeção predial pode ser dita como uma ferramenta muito importante no que tange as condições das construções, para tanto, é tido como uma maneira de controle para a manutenção das edificações, assim, o conceito de manutenção é definido pela norma técnica NBR 5674/12 como um “[...] conjunto de atividades a serem realizadas para conservar ou recuperar a capacidade funcional da edificação e de suas partes constituintes de atender as necessidades e segurança dos seus usuários [...]" (ABNT, 2012).

As inspeções são essenciais no conjunto de atividades que rege a manutenção, assim de acordo com a NBR 5674/12, inspeção significa "[...] avaliação do estado da edificação e de suas partes constituintes, realizada para orientar as atividades de manutenção". (ABNT, 2012, p. 3), para tanto, nas inspeções é necessária sua execução ser realizadas por meio de padrões organizados e ordenados para favorecer os registros e sua restauração (ANBT, 2012).

Desta maneira, compreende-se inspeção predial como a constituição de um instrumento capaz de avaliar as condições de uso e manutenção das construções verticais, onde, a mesma se faz necessária principalmente em edifícios mais antigos, pois se espera que esses apresentem mais riscos e falhas no seu interior devido à idade de projeto e depreciação dos seus ambientes, como é o caso das maiores cidades brasileiras, onde boa parte dos seus prédios apresentam aproximadamente 30 anos ou superior, e a perspectiva é que a cada ano aumente o número de construções mais antigas no meio urbano (SILVA, 2016).

A realização da atividade de inspeção predial é obrigatória nas principais cidades brasileiras cuja sua regulamentação ainda é bem recente, já que as mesmas apresentam muitos edifícios com idade de projeto avançada. Logo, é destacado em literatura que para edificações a partir de 30 anos é necessária vistoria a cada dois anos, pois “" [...] tendo em conta que quanto mais antigas são as construções, piores são suas condições de conservação e manutenção, e mais intervenções são necessárias [...] (SILVA, 2016).

Apesar de extremamente necessária para a segurança dos seus moradores, a inspeção predial ainda é tida como uma despesa desnecessária, e consequentemente as manutenções dos ambientes apontadas pelo resultado das suas inspeções são rechaçadas, o que agrava ainda mais a propagação da atividade no país, mesmo sendo sabido que manutenções em construções verticais aumentam consideravelmente o desempenho de projetos e acrescem o tempo de vida dos sistemas dos edifícios e assim reduz grandemente o risco de colapsos estruturais, como pode ser visualizado na figura 1 (PUJADAS, 2007).

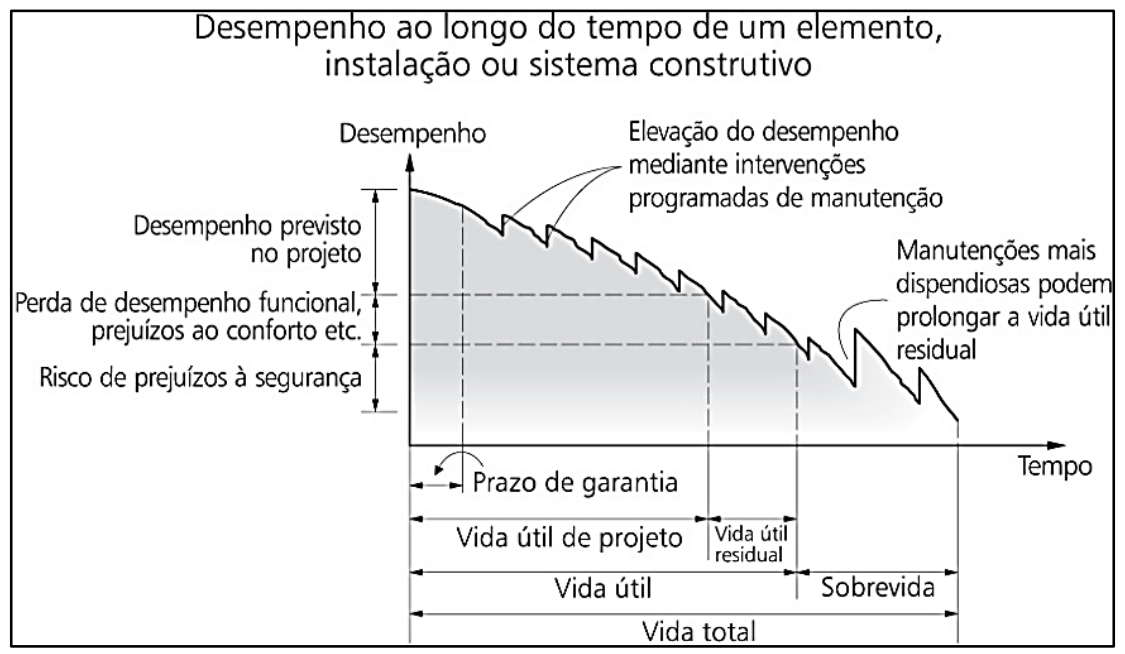

Figura 1: Desempenho ao longo do tempo. 
Aliado a esse problema, outro agravante é que ainda existem muitas divergências e pontos não esclarecidos sobre as leis, normas e regulamentações sobre a atividade, além de pouco difundido os quesitos técnicos para a execução das auditorias e vistorias no que se refere a manutenção e desempenho das construções verticais, logo, as mesmas acabam sendo de formas muito indiretas de acordo com a experiência de cada profissional que executa a atividade (VERVLOET, 2018).

\section{REGULAMENTAÇÃO DA ATIVIDADE DE INSPEÇÃO PREDIAL NO BRASIL}

Ao nível federal, apesar da necessidade de regulamentação da atividade de inspeção e manutenção predial, ainda não existe uma regulamentação por meio de lei complementar, porém, foi criado em 2013 o projeto de lei n. ${ }^{\circ} 6014$ de autoria do ex-senador da república a atual prefeito da cidade do Rio de Janeiro, Marcelo Crivella, desta maneira, atualmente o projeto de lei encontra-se finalizado e disponível para pauta na Comissão de Constituição e Justiça e de Cidadania (CCJ) (BRASIL, 2013).

O projeto de lei procura decretar a execução sistemática e periódica de inspeções em construções verticais e gera o Laudo de Inspeção Técnica de Edificação (LITE). O projeto de lei determina que seja realizado um roteiro para a aplicação da atividade e institui parâmetros e processos que devem ser seguidos com instruções presentes nas normas técnicas no que se refere a criação e elaboração do LITE. Além de, estabelecer aos municípios a responsabilidade de gerenciar os métodos e sistemas de registro e controle das atividades de inspeção e vistoria predial e disponibilizar para a população seus dados. (BRASIL, 2013).

Neste contexto, percebe-se uma preocupação com segurança das construções verticais, geralmente ocorridas após algum grande acidente estrutural grave envolvendo edificações, logo surgem diversos decretos e leis municipais que procuram estabelecer parâmetros e indicadores que regulem a atividade de inspeção predial para as edificações já construídas, tal fato pode ser observado nas cidades, como no Rio de Janeiro-RJ, com a lei n. ${ }^{\circ} 6400,2013$, em Vitória-ES, com a lei n. ${ }^{\circ}$ 8.992 de 2016 e em Fortaleza-CE, com a lei n. ${ }^{\circ} 9.913$ de 2012, que passa a ser obrigatória a inspeção predial regular (IBRAENG, 2015).

Com a edição e publicação de leis, procedimentos e normas municipais acontecendo de forma pontual em várias partes do país simultaneamente, torna bem heterogenia o que de fato deve ser levado em consideração na regulamentação da atividade de inspeção predial, pois cada legislação, é baseada na interpretação das normas técnicas existentes da Associação Brasileira de Normas Técnicas (ABNT) pelo executivo e legislativo municipal, assim, várias questões não esclarecidas são levantadas em relação ao método, profissionais, hierarquias, órgãos públicos, onde documentos são criados, processos iniciados e não terminados, ou seja, é notável a desorganização da atividade, o que consequentemente gera deficiências na lisura do seu processo, aliada a falta de fiscalização (OLIVEIRA, 2013; VERVLOET, 2018).

Assim, no que diz respeito ao cenário brasileiro sobre a processo descrito, até a publicação deste artigo, não havia sido publicada nenhuma norma técnica da ABNT que estabelece a regulamentação da inspeção predial em território nacional, visto que a ABNT, espera um posicionamento do legislativo enquanto órgão criador de leis, tratar oficialmente da criação da atividade (BRASIL, 2013).

Neste sentido, os poderes executivos e legislativos municipais espalhados pelo Brasil, baseiam suas leis nas diversas normas da ABNT e de outros órgãos de interesse ao setor, que tratam de algum aspecto a inspeção predial (SILVA, 2016), como é o caso das orientações em relatórios técnicos de Conselhos Regionais de Engenharia e Agronomia (CREA), NBR 15.575-1, que trata de regulações de documentos de inspeção em construções verticais, a mesma norma ainda indica seguir recomendações da Norma de Inspeção Predial Nacional do Instituto Brasileiro de Avaliações e Perícias de Engenharia, onde sua última revisão foi publicada em 2012 (IBAPE, 2012).

A Norma de Inspeção Predial Nacional (IBAPE, 2012) representa um avanço quanto às recomendações técnicas da atividade específica da inspeção predial, já que o órgão regulador nacional (ABNT) não possui normativo publicado sobre o assunto (VERVLOET, 2018, p. 4).

Neste contexto, a norma veio para estabelecer diretrizes no cenário nacional que se encontra atualmente com carências nas regulamentações da atividade de inspeção e manutenção das construções verticais, desta forma a criar conceitos, terminologia da atividade, convenções, notações, critérios e procedimentos relativos à inspeção predial (IBAPE, 2012). 


\section{METODOLOGIA}

Diante das justificativas citadas anteriormente, para alcançar os objetivos deste artigo, a abordagem metodológica presente nesta publicação tem a finalidade de elaborar uma revisão bibliográfica baseada numa pesquisa documental e qualitativa a respeito do tema sobre inspeção predial: perspectivas atuais e futuras diante do cenário de colapsos estruturais ocorridos na cidade de Fortaleza/CE em 2019.

Desta forma, no que se refere aos procedimentos da pesquisa, a mesma é classificada como pesquisa bibliográfica com abordagem qualitativa, pois a:

Pesquisa bibliográfica: quando elaborada a partir de material já publicado, constituído principalmente de: livros, revistas, publicações em periódicos e artigos científicos, jornais, boletins, monografias, dissertações, teses, material cartográfico, internet, com o objetivo de colocar o pesquisador em contato direto com todo material já escrito sobre o assunto da pesquisa (PRODANOV; FREITAS, 2013, p. 54).

No que se refere a pesquisa documental, a mesma pode ser definida como a investigação baseada na fonte de coleta de dados em documentos, escritos ou não, compreendendo o que se chama de fontes primarias e secundárias (MARCONI; LAKATOS, 2003).

Enquanto a pesquisa bibliográfica se utiliza fundamentalmente das contribuições dos diversos autores sobre determinado assunto, a pesquisa documental vale-se de materiais que não receberam ainda um tratamento analítico, ou que ainda podem ser reelaborados de acordo com os objetivos da pesquisa (GIL, 2008 p. 51).

Assim, segundo Prodanov e Freitas (2013), a pesquisa bibliográfica se baseia na literatura científica já publicada sobre as intervenções metodológicas propostas pelo projeto, assim, ao realizar a compilação dos estudos e das diferentes visões a respeito do tema de acordo com uma abordagem qualitativa conforme mostra a definição a seguir.

Pesquisa qualitativa: considera que há uma relação dinâmica entre o mundo real e o sujeito, isto é, um vínculo indissociável entre o mundo objetivo e a subjetividade do sujeito que não pode ser traduzido em números. A interpretação dos fenômenos e a atribuição de significados são básicas no processo de pesquisa qualitativa. Seu significado são os focos principais de abordagem (PRODANOV; FREITAS, 2013, p. 71).

Com isso, o presente artigo é composto de 4 etapas. A primeira consiste em uma introdução que aborda a problemática, justificativa e motivações para esta pesquisa. A etapa seguinte propõe a caracterização dos conceitos, definições básicas empregadas neste trabalho a partir do estudo da literatura científica, assim conceituando a inspeção predial, regulamentações existentes em níveis federais e municipais onde aborda as falhas no atual sistema e a necessidade da aprovação de uma lei de nível federal para a aplicação da atividade.

Na terceira etapa é destacada o avanço da movimentação ao nível municipal da cidade de Fortaleza quando a promoção da atividade de inspeção predial frente aos colapsos estruturais ocorridos em seu meio urbano que acarretaram o desabamento de dois edifícios em diferentes regiões da cidade, a partir de documentos, leis, pautas técnicas praticadas encontradas na revisão de literatura que trouxeram algum benefício e contribuíram para a elaboração deste estudo.

A quarta e última etapa traz as conclusões a respeito das principais informações obtidas através do estudo e elaboração deste artigo sobre importância da regulação, aplicação e fiscalização da atividade de inspeção predial, e como os recorrentes acidentes envolvendo colapsos estruturais contribuem para a sua regulamentação, fiscalização e divulgação da sua necessidade.

O levantamento bibliográfico foi realizado através das principais bases de dados existentes, dentre eles, Google Acadêmico, Scielo, Ebsco Host e Periódicos Capes, assim, neste artigo foram empregados livros, teses de doutorado, dissertações de mestrado e artigos publicados em jornais e revistas, memorandos, anúncios oficiais durante o período de 2007 a 2019. 


\section{RESULTADOS E DISCURSSÕES}

Nesta seção são contextualizados as recentes quedas de edifícios acontecidos causados por falhas estruturais no país e são abordados os desabamentos ocorridos no município de Fortaleza no ano de 2019, frente a isso, é exibido uma evolução das discussões sobre a regulamentação atividade da inspeção predial na capital cearense, bem como, sua fiscalização por órgãos competentes.

\subsection{Recentes Colapsos Estruturais no Brasil}

Recentemente, não foram poucos os casos registrados de colapsos estruturais que causaram grandes tragédias nas principais cidades brasileiras. Dentre elas, é destacado a queda de um edifício de 3 andares em outubro de 2010, que resultou na morte de quatro pessoas, no bairro de Cidade Nova, área central da cidade do Rio de Janeiro, onde, segundo a defesa civil a falha foi estrutural e o prédio não havia sido vistoriado devido à inexistência de solicitações para a mesma.

Pouco mais de um ano e meio depois, em janeiro de 2012, uma obra de reforma no nono pavimento de prédio ocorrido no centro da cidade do Rio de Janeiro acabou abalando a sua estrutura portante e dos empreendimentos da vizinhança que resultou na queda de 3 edifícios no local.

Em março de 2018, no bairro de Pituaçu em Salvador ocorreu um desabamento de um prédio de 3 andares, o colapso estrutural se deu após um período de fortes precipitações na capital baiana, porém, o empreendimento não se encontrava em área de risco segundo a defesa civil, mas de toda forma, a construção era irregular e acarretou a morte de quatro vítimas.

Já em abril de 2019, dois edifícios residenciais com 5 andares cada, desabaram após fortes chuvas na comunidade da Muzema, bairro de Itanhangá, localizado na Zona Oeste da cidade do Rio de Janeiro, onde causou a morte de 24 pessoas (figura 2). Ambos os empreendimentos foram concebidos de forma irregular e estavam em processo de interdição segundo a prefeitura da cidade.

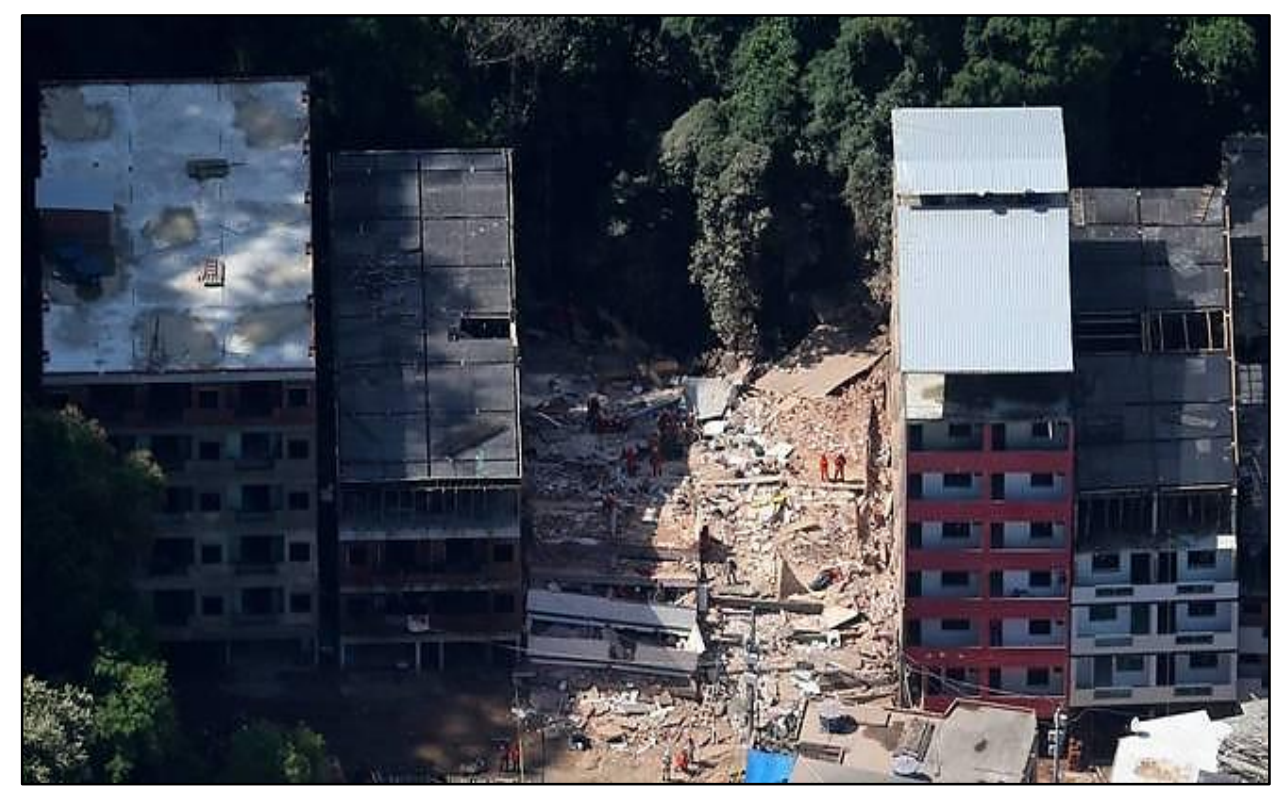

Figura 2: Escombros após o desabamento de dois edifícios residenciais na comunidade da Muzema

Mesmo diante de vários casos de desabamentos causados por falhas estruturais resultando na morte de várias vítimas, e a crescente desconfiança na qualidade das atividades de construção civil no país, ainda é lendo o andamento de políticas de inspeção predial em muitas cidades brasileiras.

A capital cearense, Fortaleza, ainda tem muito a avançar nesse quesito, onde, somente no ano de 2019 foram registrados dois grandes colapsos estruturais em edifícios de diferentes zonas da cidade, que mostra a necessidade urgente de implantação de verdadeiras políticas de inspeção predial que regulamente, fiscalize e gerencie a atividade dentro do setor na cidade. 


\subsection{Edifício Benedito Cunha}

O Edifício Benedito Cunha, localizado no bairro Maraponga, desabou parcialmente no dia $1^{\circ}$ de julho, devido à ruptura das colunas de sustentação, ficando inclinado em 15 graus (figura 3). A justiça determinou que os proprietários demolissem o restante do prédio em até 5 dias, com pena de $\mathrm{R} \$ 5.000$ de multa por dia em caso de descumprimento (TRINDADE, 2019).

Ao todo, segundo a prefeitura de Fortaleza, 16 famílias moravam no local e foram desalojadas as pressas sem o direito de retorno ao imóvel para recuperação de pertences. Por recomendação da Defesa Civil 15 outras famílias, moradoras do entorno, tiveram que deixar suas casas devido ao risco de desabamento total do edifício atingir as outras residências do local (TRINDADE, 2019).

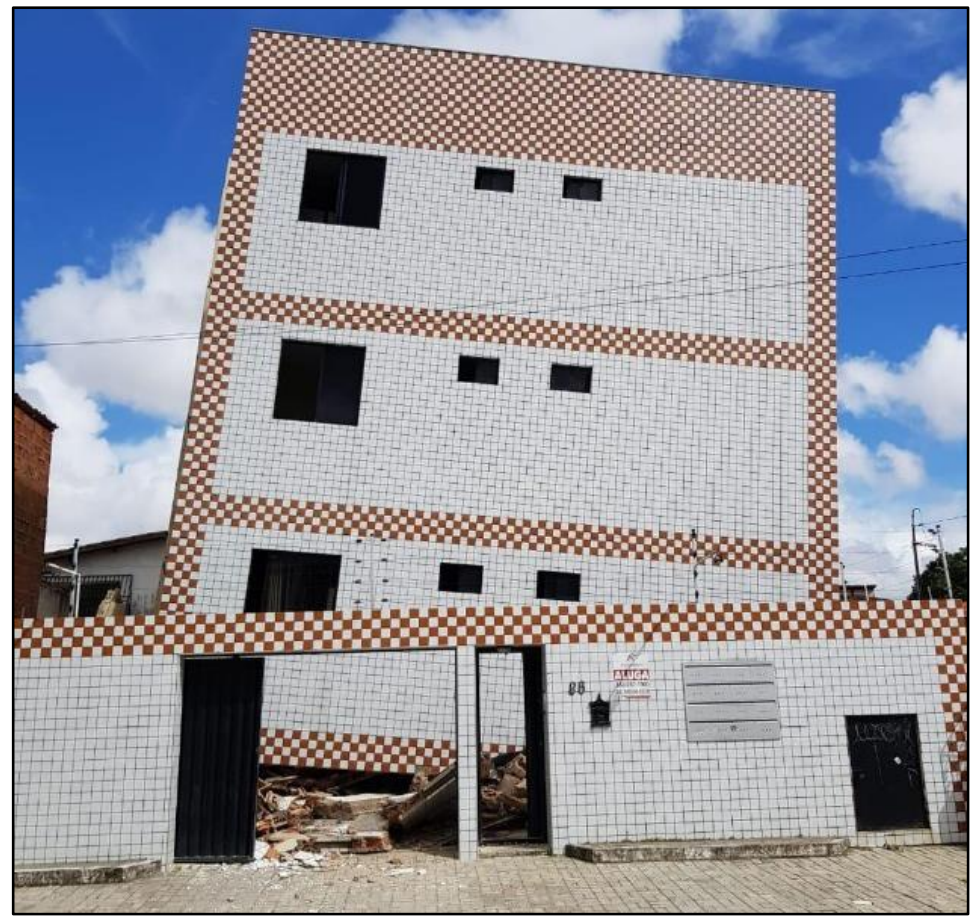

Figura 3: Edifício Benedito Cunha após colapso

O relatório de vistoria emitido, dois dias antes do desabamento do prédio, em 30 de maio, relatou que não havia sido encontrado "qualquer indício de colapso estrutural, total ou parcial no edifício Benedito Cunha". O parecer técnico foi o terceiro serviço registrado no Conselho Regional de Engenharia e Agronomia do Ceará (Crea-CE) sobre a estrutura (CN News, 2019).

Neste sentido, além da regulamentação da atividade de inspeção predial na cidade de fortaleza, é necessária uma fiscalização por parte dos órgãos públicos nos laudos emitidos e registrados, pois, existem laudos realizados que atestam a segurança de um empreendimento com dados inverídicos e/ou fraudados como ocorrido no caso do edifício Benedito Cunha.

\subsection{Edifício Andrea}

O edifício residencial Andrea, localizado na zona nobre da cidade de Fortaleza, no Bairro Dionísio Torres, desabou em 15 de outubro. A edificação possuía sete andares (figura 4), e estava com problemas estruturais nas colunas de sustentação. Com o colapso e desabamento (figura 5), nove pessoas morreram e sete foram resgatadas com vida dos escombros do prédio ao longo de mais de 24 horas de resgate realizado pelo corpo de bombeiros.

O registro do imóvel é referente ao ano de 1982 e sua construção foi em realizada em 1995. Após a inauguração, o empreendimento raramente passava por vistorias da Prefeitura de Fortaleza, já que em 2012 a prefeitura sancionou uma lei obrigando os edifícios a apresentarem de forma periódica certificados de vistoria, garantindo a manutenção da estrutura e qualidade da construção frente a possíveis patologias. 
No entanto, as fiscalizações sempre foram adiadas, a primeira ocorreria no primeiro semestre do ano de 2015, em seguida para o ano de 2016 e mais tarde para o fim do ano de 2017 (MADEIRO, 2019). Porém, no dia do desabamento, a prefeitura de Fortaleza informou que o imóvel era considerado irregular, pois não existiam dados do imóvel nos registros do município.

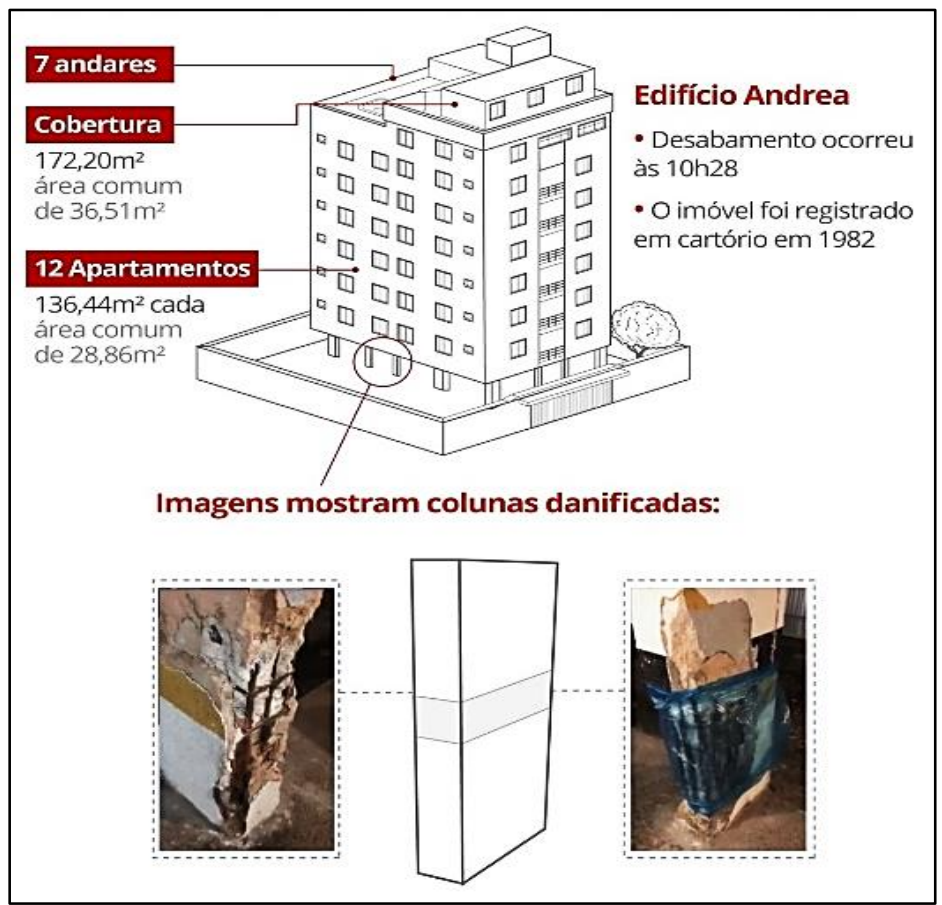

Figura 4: Estrutura do Edifício Andrea

Segundo Holanda, depois da tragédia com Edifício Andrea, o nível de atenção tanto do poder público, como de síndicos e de moradores ficou elevado e todos juntos devem, redobrarem a atenção. "Nosso nível de percepção de alerta de segurança deve ser elevado a partir dessa tragédia. Principalmente nas edificações verticalizadas", ressaltou (XEREZ; ALVES, 2019, s.p).

Desta forma "ele reforça que essa deve" ser uma preocupação de todos. Não somente uma preocupação do poder público apenas, nem tampouco do síndico. Deve ser de toda a comunidade, que todos aqueles que habitam naquela edificação tenham a responsabilidade" (XEREZ; ALVES, 2019, s.p). O engenheiro técnico apontado como responsável por reforma no edifício esclareceu à polícia que começaria as obras no prédio no último dia 15 de outubro, data em que a edificação desabou.

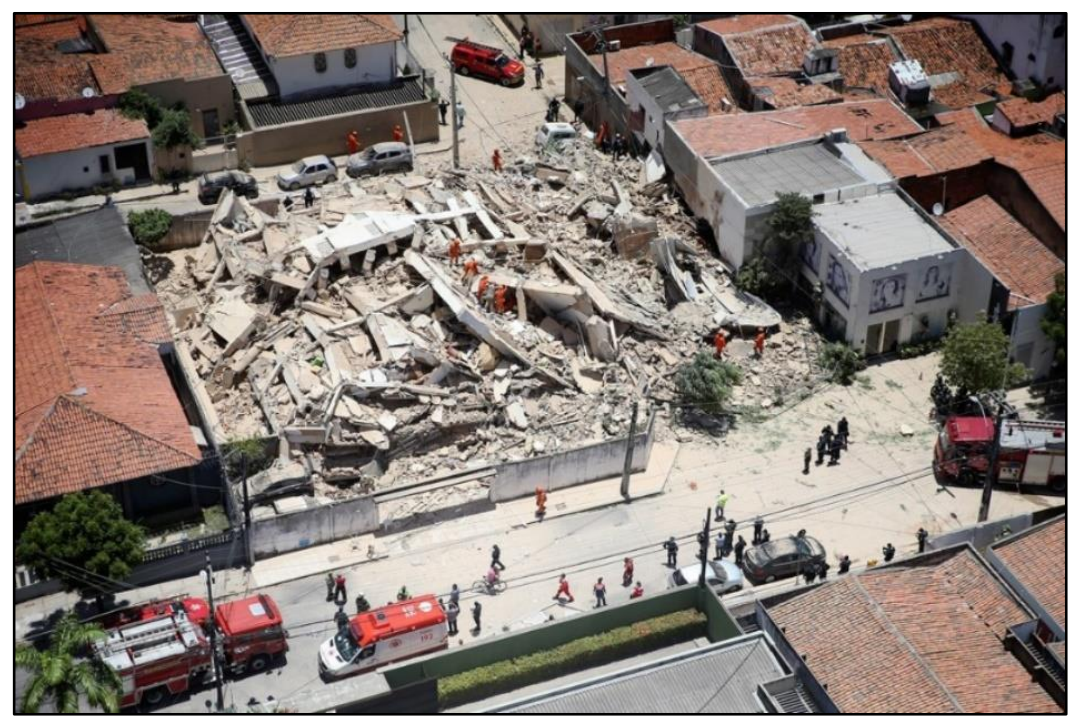

Figura 5: Escombros Edifício Andrea 
Esses dados reforçam ainda mais a necessidade do comprimento da legislação de inspeção predial, pois a sua negligência pode envolver sérios riscos incalculáveis, tanto em relação ao edifício, quanto principalmente ao valor inestimável da perda do lar das famílias que ali moravam e das vidas perdidas. Não somente o prédio em questão, mas também toda a vizinhança é afetada, suas casas precisam serem interditadas por metidas de segurança e tem toda sua rotina alterada.

\subsection{Discussões sobre a Inspeção Predial em Fortaleza/Ce.}

Assim como as cidades de Rio de Janeiro e Vitória, impulsionado pela pressão do setor, em Fortaleza, foi criada a lei n. ${ }^{\circ}$ 9913, de 16 de julho de 2012 que “[...] dispõe sobre obrigatoriedade de vistoria técnica, manutenção preventiva e periódica das edificações e equipamentos públicos ou privados no âmbito do município de Fortaleza, e dá outras providências [...]” (FORTALEZA, 2012, p. 1).

Após 4 anos de criação da lei com intuito de regulamentar o setor e apoiada pelo decreto de $n .^{\circ} 13616$, de 23 de junho de 2015 regulamenta lei n. ${ }^{\circ} 9913$, de 16 de julho de 2012, que dispõe sobre as regras gerais e específicas a serem obedecidas na manutenção e conservação das edificações no município de fortaleza, e dá outras providências (FORTALEZA, 2012, p. 1). A lei institui que a partir de 2016 daria início as fiscalizações sendo nas edificações com até 20 anos a obrigação de fazer a inspeção e emissão do Certificado de Inspeção Predial (CIP) a cada 5 anos. Prédios de 21 a 30 anos, se faz necessário realizar a vistoria a cada três anos. Para os empreendimentos mais antigos de 31 a 50 anos, as vistorias devem ser a cada dois anos. E nos edifícios acima de 50 anos é preciso fazer o serviço todo ano (FORTALEZA, 2012).

A prefeitura de Fortaleza, em abril de 2016, por sua vez, adiou por um ano o início da fiscalização em prédios da capital, onde a mesma alega que é necessário realizar durante este período um trabalho educativo e treinamento de profissionais de fiscalização. Após esse período, em abril de 2017, o executivo municipal, novamente optou pelo adiamento em 60 dias justificando adequações na lei. Após esse período em agosto de 2017, a fiscalização foi prorrogada outra vez, alegando demanda de síndicos e administradoras de condomínios, conforme a figura 6.

\section{Cronologia da legislação}

Seis anos após a criaçao da lei, as fiscalizaçøes ainda nao foram iniciadas pela prefeitura

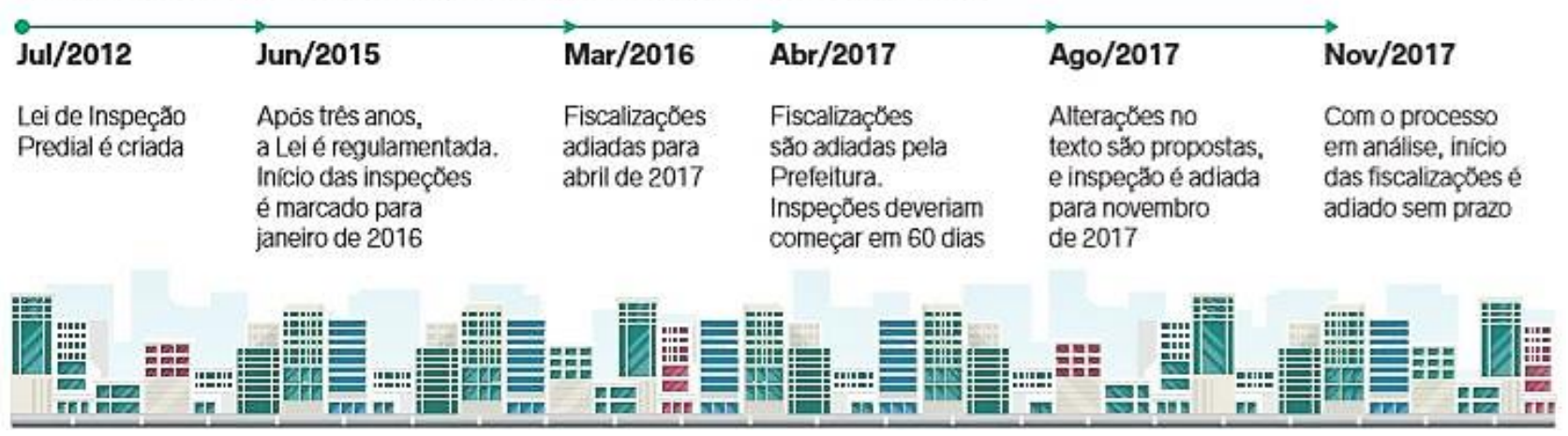

Figura 6: Cronologia da legislação relativa à inspeção predial na cidade de Fortaleza

Desta forma, por vezes a Agência de Fiscalização de Fortaleza justifica as prorrogações como uma forma de espera para a conclusão dos estudos técnicos para uma nova proposta lei sobre a atividade, com a ajuda de entidades do setor para melhora do atual texto, sem definição de prazo para conclusão.

Após os acidentes ocorridos na cidade envolvendo casos de colapsos estruturais parciais e totais, foi criada a Comissão Especial de Acompanhamento de Inspeção Predial do Município de Fortaleza, sendo responsável na atuação de fiscalização do processo de inspeção predial, para evitar novos desabamentos, sendo realizado pela prefeitura municipal, em parceria com o Ministério Público do Estado (MPCE) e Conselho Regional de Engenharia e Agronomia do Ceará (Crea-CE).

Atualmente o cenário na cidade de Fortaleza se apresenta ainda com dificuldades visto que o cumprimento da Lei de Inspeção Predial depende da aprovação da Câmara Municipal que ainda segue em discutindo o projeto. No que se refere às fiscalizações, o MPCE mapeou e criou uma lista com 250 estruturas a serem vistoriados na capital. Porém, pouco avançou. Segundo a prefeitura do município até janeiro de 2020, somente 74 prédios haviam sido vistoriados. O MPCE informou que nenhum cronograma sobre a atividade foi entregue, ultrapassando o prazo de 30 dias que foi determinado. 
Assim, em janeiro de 2020, a prefeitura municipal por meio da AGEFIS, solicita a Comissão de Inspeção predial do Ministério Público do Ceará (MPCE) a extinção da Portaria 7452/2019 que instituía um grupo de trabalho com objetivo de fiscalização e vistoria nos empreendimentos residenciais e comerciais de Fortaleza que apresentam problemas estruturais com risco de desabamento.

\section{CONCLUSÃO}

Conclui-se então, que seis anos após a criação da lei, as fiscalizações ainda não foram iniciadas pela prefeitura de Fortaleza, pouco se avançou nas questões legislativas sobre a real e efetiva execução das atividades de inspeção e manutenção predial, onde a mesma aguarda modificações no texto base, bem como na sua futura regulamentação e aguardada aplicação.

A lei continua em vigor, porém sem força no seu efetivo cumprimento e fiscalização, onde a maioria dos quase 74000 empreendimentos na capital que se enquadram na lei, ainda seguem sem o Certificado de Inspeção Predial (CIP), que certifica a vistoria e inspeção que garante a segurança estrutural do edifício, onde consequentemente, preserva a vida de seus moradores e da circunvizinhança. A Prefeitura de Fortaleza informa que a atividade de inspeção predial não é um ato municipal e que cabe a iniciativa privada e suas instituições a execução da lei, ou seja, a mesma informa que atualmente a máquina pública não tem capacidade de fiscalizar todos os imóveis que se enquadram na lei.

Assim como, o Conselho Regional de Engenharia e Agronomia do Ceará (Crea-CE) esclarece que não possui autoridade para cobrar dos responsáveis pelos empreendimentos a realização de suas atividades de inspeção predial e que cabe ao poder público essa tarefa, mas informa que todos os serviços ligados a essa área devém ser realizados por profissionais técnicos registrados no seu conselho com a emissão de Anotações de Responsabilidade Técnica (ART).

Assim, este trabalho alcançou o objetivo de enquadrar o atual cenário da regulamentação e fiscalização da atividade de inspeção predial na cidade de Fortaleza, expondo os principais pontos e acontecimentos importantes que regem a atividade no município, bem como, suas perspectivas futuras, que no momento, ainda não são positivas, visto que os órgãos municipais e privativos, ainda se posicionam de forma e se ausentar das responsabilidades da gestão desta atividade.

Espera-se que nos próximos meses seja enfim realizado a nova proposta de lei com a contribuição de entidades do ramo, com seus objetivos e planos bem definidos, com sua devida fiscalização para evitar novos acidentes envolvendo colapsos estruturais.

\section{REFERÊNCIAS}

ASSOCIAÇÃO BRASILEIRA DE NORMAS TÉCNICAS - ABNT. NBR 15575: Edificações habitacionais Desempenho Parte 1: Requisitos gerais. Rio de Janeiro, 2013.

ABNT. NBR 5674: Manutenção de edificações - Requisitos para o sistema de gestão de Manutenção. Rio de Janeiro, 2012.

BRASIL. CÂMARA DOS DEPUTADOS. PL 6014/2013 Informações de Tramitação. Disponível em: https://www.camara.leg.br/proposicoesWeb/fichadetramitacao?idProposicao=585637. Acesso em: 10 dez. 2019. Brasília, DF, 2019.

FREITAS, C.; XEREZ, G.; ALMEIDA, V. Prédio residencial desaba em Fortaleza e deixa feridos. G1 Portal de Notícias. 15/10/19. Disponível em: https://g1.globo.com/ce/ceara/noticia/2019/10/15/predio-residencial-desaba-em-fortaleza. Acesso em: dez. 2019.

FORTALEZA. Lei Municipal No 9913, de 16 de julho de 2012. Dispõe sobre obrigatoriedade de vistoria técnica, manutenção preventiva e periódica das edificações e equipamentos públicos ou privados no âmbito do município de Fortaleza, e dá outras providências. Fortaleza, 2012.

FORTALEZA. Decreto Municipal No 13.616, de 23 de junho de 2015. Regulamenta lei no 9913 , de 16 de julho de 2012, que dispõe sobre as regras gerais e específicas a serem obedecidas na manutenção e conservação das edificações no município de fortaleza, e dá outras providências. Fortaleza, 2015. 
GIL, A. C. Métodos e técnicas de pesquisa social. 6. Ed. São Paulo: Atlas, 2008.

GOMIDE, T. L.F.; NETO, J. C. P. F.; GULLO, M. A. Normas Técnicas para Engenharia Diagnóstica em Edificações. 1. ed. São Paulo. PINI. 2009.

INSTITUTO BRASILEIRO DE AUDITORIA DE ENGENHARIA - IBRAENG. OT 003-2015- IBRAENG: Inspeção Predial e Auditoria Técnica Predial. Fortaleza, 2015. Disponível em http://www.ibraeng.org/pub/normas. Acesso em 10 dez. 2019.

INSTITUTO BRASILEIRO DE AVALIAÇÕES E PERÍCIAS DE ENGENHARIA DE SÃO PAULO - IBAPE. Inspeção Predial: Checkup predial: guia da boa manutenção. 3. ed. São Paulo. LEUD. 2012.

LEOMAR, J. Um mês depois, perícia sobre desabamento do Edifício Andrea, em Fortaleza, ainda não foi concluída. G1 Ce. Disponível em: https:/g1.globo.com/ce/ceara/noticia/2019/11/15/um-mes-depois-pericia-sobre-desabamento-doedificio-andrea-em-fortaleza-ainda-nao-foi-concluida.ghtml. Acesso em 20 dez 2019.

CN News. Laudo aponta que não havia risco de deterioração de prédio. Disponível em: http://cnews.com.br/cnews/noticias/138590/laudo_aponta_que_nao_havia_risco_de_deterioracao_de_predio. Acesso em 20 dez 2019.

MADEIRO, C. Fortaleza ignora há anos fiscalização prevista em lei para inspeção predial. Cotidiano, UOL. Disponível em: https://noticias.uol.com.br/cotidiano/ultimas-noticias/2019/10/16/fortaleza-ignora-ha-anos-fiscalizacaoprevista-em-lei-para-inspecao-predial.htm. Acesso em $20 \mathrm{dez} 2019$.

MARCONI, M. de A.; LAKATOS, E. M. Técnicas de pesquisa: planejamento e execução de pesquisas, amostragens e técnicas de pesquisa, elaboração, análise e interpretação de dados. 7. ed. São Paulo: 2009.

OLIVEIRA, C. S. P. de. Análise Crítica de Experiências e Discussão de Estratégias para Implantação de Leis de Inspeção de Elementos de Fachada. [s.1.: s.n.] 2013.

PRODANOV, C.C.; FREITAS, E. Metodologia do Trabalho Científico: Métodos e técnicas da pesquisa e do trabalho acadêmico. 2. Ed. Novo Hamburgo: Universidade Feevale, 2013.

PUJADAS, F. Z. A. Inspeção Predial: Ferramenta de Avaliação da Manutenção. In: CONGRESSO BRASILEIRO DE ENGENHARIA DE AVALIAÇÕES E PERÍCIAS, 14, 2007, Salvador. Anais. Salvador: IBAPE, 2007.

SILVA, W. L. Inspeção predial: diretrizes, roteiro e modelo de laudo para inspeções em edificações residenciais da cidade do Rio de Janeiro. Projeto de Graduação, Curso de Engenharia Civil, Universidade Federal do Rio de Janeiro, Escola Politécnica. Rio de Janeiro, RJ, 2016.

TRINDADE, W. Demolição do prédio que desabou parcialmente na Maraponga deve acontecer até quinta. 2019. Disponível em: https://www.opovo.com.br/noticias/demolicao-do-predio-que-desabou-parcialmente-na-marapongadeve-acontecer-ate-quinta.html. Acesso em: 20 dez 2019.

VERVLOET, S. Análise de indicadores para execução de inspeção predial regular obrigatória e diretrizes para o corpo técnico. Dissertação (Mestrado em Engenharia Civil com ênfase em Construção Civil). Universidade Federal do Espírito Santo. Vitória: 2018. 156p.

VIEIRA, F. N. Proposta de elaboração de plano de manutenção para edificações a partir da obrigatoriedade legal da inspeção predial no contexto urbano das Cidades. Rio de Janeiro, 2015. Dissertação (Mestrado) - Programa de Engenharia Urbana, Escola Politécnica, Universidade Federal do Rio de Janeiro, Rio de Janeiro, 2015.Disponível em: http://dissertacoes.poli.ufrj.br/dissertacoes. Acesso em: 16 dez. 2019.

XEREZ, G. ALVES, M. Laudo sobre desabamento de prédio em Fortaleza deve ser concluído em 10 dias. G1 Ceara. 2019. Disponível em: https://g1.globo.com/ce/ceara/noticia/2019/10/21/pericia-inicia-investigacao-sobre-desabamentodo-edificio-andrea-em-fortaleza-bombeiros-darao-apoio.ghtml. Acesso em 20 dez 2019. 